\title{
Revisiting the Validity and Reliability of the Gallup Workplace Audit in a South African Petrochemical Company
}

\author{
Werner Havenga ${ }^{1 *}$, Conrad Brand ${ }^{2}$ and Jan Visagie ${ }^{* *}$ \\ ${ }^{1}$ School for Human Resource Sciences, North-West University \\ ${ }^{2}$ Department of Industrial Psychology and People Management, University of Johannesburg \\ ${ }^{1}$ E-mail: "<Werner.havenga@nwu.ac.za $>$, "“<Jan.visagie@nwu.ac.za $>$
}

KEYWORDS Gallup. Engagement. Petrochemical Company. Workplace. Cross-sectional Survey. Kaiser-MeyerOlkin

\begin{abstract}
Satisfaction at work has become a widespread focus of researchers. The Gallup Q12 Workplace Audit is an instrument that measures employee engagement on a 12 -item scale. The aim of this exploratory study was to revisit the validity and reliability of the Gallup Workplace Audit (GWA) as a measure of employee engagement in a petrochemical company. Furthermore, the study aimed to determine whether the GWA, which is an international survey, can be used effectively in South Africa. A cross-sectional survey design with an accidental sample $(\mathrm{N}=2$ 588) was used. First results showed that none of the items needed to be eliminated from the scale, and that the scale itself had a very high reliability. Descriptive statistics such as frequency counts were used to describe the sample. Acceptable internal consistency was reached through an exploratory factor analysis which resulted in a one-factor model of work engagement. The results confirmed that this international survey can be utilised effectively in the South African context. Recommendations for future research conclude this article.
\end{abstract}

\section{INTRODUCTION}

Organisations are continuously grappling with the challenge of remaining competitive (Koyuncu et al. 2006). This challenge has heightened performance pressures and has led to the introduction of new technological advances in operations and management, an increasingly diverse workforce and the globalisation of business (Burkea and Ngbe 2006). It has become more evident to organisational leaders that their human resources are key to increasing their productivity, more than other competitive resources such as technology, capital and products (Lawler 2003; Burke and Cooper 2005).

Organisations have traditionally been relying on financial and business measures to measure their performance, value and health (Koyuncu et al. 2006). Although financial measures such as profitability, revenue and cash flow remain important indicators of business performance, the so-called "soft", human-orientated leadership-styles and measures such as employee wellness, attitudes and perceptions are gaining greater recognition (Müller and Turner 2010). It is because of this that people engagement in business performance is becoming part of strategy formulation in businesses.

Deloitte surveyed 531 South African human resource and non-human resource executives around the world to understand people issues facing companies (De Beer 2007). More than $85 \%$ of the participants said that people were vital to all aspects of a company's performance, particularly to strategic challenges such as responding to increased competition, developing new products and services, and dealing with advances in technology. The survey further indicated that more than $60 \%$ of senior business executives already considered people issues "very significant" or "highly significant" to strategic decision making and that this figure was expected to reach $90 \%$ in the next three to five years. Joo and Mclean (2006) support the view and state that engaged employees are strategic for sustained competitive advantage.

However, waves of downsizing, increasing employer demands, growing job disenchantment and the continuous introduction of new technologies have taken their toll. According to Conradie (2005), South African and international research across industries consistently reveals that a minority of workers - on average $20 \%$ - are passionate about their jobs and committed to their organisations. He further states that the annual Deloitte "Best Company to Work For" survey has revealed a significant trend, namely that for the past four years job satisfaction has consistently been ranked as the most critical element in competitive advantage. Job 
satisfaction, in turn, is related to employee engagement (Demerouti and Cropanzano 2010). A meta-analysis conducted by the Gallup Organisation concluded that the most profitable work units of companies have people who do what they do best, work with people they like and have a strong sense of psychological ownership of the outcomes of their work (Shuck 2011).

The interest in employee engagement has grown significantly in recent years (Saks 2006). A number of studies have shown that employee engagement predicts employee outcomes, organisational success and financial performance (Truss et al. 2013). According to a 2004 highperformance workforce study (Arnott and Soobiah 2007a), there is a strong correlation between financial performance and the priority that organisations place on human capital development.

Blanchard (2007) states that high-performing organisations channel the energy of everyone in the organisation towards a triple bottom line: provider of choice, employer of choice and investment of choice. Being the employer of choice means finding ways to attract and retain competent workers. Today's workers generally want more from their employers. They seek opportunities to make contributions that are valued and rewarded, involve and empower them, develop skills, advance their position and allow them to make a difference (Blanchard 2007).

There is growing evidence that competitive organisations need to treat their employees as an integral part of business so as to tap their full potential (Parker 2008). New economy leadership requires of organisations to craft their business and engage people in a way that will create spaces and places that offer compelling and joyful opportunities that will allow people to flourish (Nel 2008).

To summarise, there can be little doubt that employee engagement is the issue of the moment (Employee Engagement Report 2006). Organisations around the world are trying to engage employees so as to enhance their performance and improve business outcomes. There is also growing interest in employee engagement in South Africa, and for the same reason as elsewhere. This creates the need to determine whether international surveys can be used effectively in South Africa. Since the GWA is a prime example of such surveys, this exploratory study set out to investigate its applicability to our country.

\section{Work Engagement}

Much of what has been written about employee engagement comes from practitioner literature and consulting firms, that is, from practice rather than theory and empirical research (Robinson et al. 2004). Bhatnagar (2007) states that the confusion in the literature regarding employee engagement relates to overlapping constructs such as organisational commitment, intrinsic motivation, and employee involvement, passion and dedication to work. Notwithstanding, Saks's (2006: 613) research on the antecedents and consequences of employee engagement concludes that "employee engagement is a meaningful construct that is worthy of future research".

Webster (2011) confirms the credo of "heads, hands and hearts" with regard to talent management. It is hearts (or passion, a person's intrinsic motivation) that are the essence of employee engagement. Vale (2011: 1) states that "employee engagement goes beyond satisfaction and motivation; engaged employees give of their best and have a contagious enthusiasm; are advocates of their company, and invest extra effort to go above and beyond their given role". Mollen and Wilson (2010) state that the Gallup organization defines engagement as an individual's involvement, satisfaction, and enthusiasm for work where individuals are emotionally connected to others at work and are cognitively vigilant. According to Cropanzano and Mitchell (2005), such a relationship evolves over time and produces mutual trust, loyalty and commitment, but only as long as the parties abide by certain rules of exchange.

Rothbard (2001) also defines engagement as psychological presence, but goes further by stating that it involves two critical components: attention and absorption. According to Saks (2006), burnout researchers such as Maslach et al. (2001) define engagement as the opposite or positive antithesis of burnout. According to Maslach et al. (2001), engagement is characterised by energy, involvement and efficacy, the direct opposite of the three burnout dimensions of exhaustion, cynicism and inefficacy.

Saks (2006) states that although the definition and meaning of engagement in the practitioner literature often overlap with the definition and meaning of other constructs, in the academic literature engagement has been defined as a 
distinct and unique construct that consists of cognitive, emotional and behavioural components that are associated with individual role performance.

From the above definitions it is clear that one central theme emerges which is that employee engagement is an emotional commitment the employee has to the organization and its goals, and not just relate to employee happiness or employee satisfaction.

On the other hand, disconnection of an employee from their work roles can be described as disengagement. This is mainly to protect themselves mentally and physically for perceived or real threats. This disconnection can be operationalized in terms of having to separate work life from home or outside activities or beliefs, a failure to find meaning in the work itself, a lack of belief in the purpose of the organization, or a sense that the individual is powerless to overcome stagnation and frustration in the work environment (Wollard 2011).

Luthans and Peterson (2002) cite findings that indicate that employees who are personally engaged (cognitively and/or emotionally) as opposed to those who are disengaged are not only more satisfied, but also more productive. This is similar to what Gallup has found using its empirically validated GWA in measuring engagement. A comparison of the GWA(Buckingham and Coffman 1999) with Kahn's (1990) theoretical dimensions of engagement shows an apparent conceptual fit, which fit provides theoretical grounding for a better understanding of employee engagement and for measuring employee engagement by means of the GWA.

\section{Other Perspectives on Work Engagement}

The Global Study of Employee Engagement, published by employee research and consulting firm ISR (International Survey Research), identifies four global drivers of employee engagement, namely leadership, career development, empowerment and image. ISR formally defines employee engagement as "a process by which an organization increases commitment and contribution of its employees to achieve superior business results". Engagement, according to ISR, is a combination of an employee's cognitive, affective and behavioural commitment to a company.
Andrew Brown of Mercer Delta Consulting views engagement as a progressive combination of satisfaction, motivation, commitment and advocacy resulting from an employee's movement up the engagement pyramid:

- Satisfaction, the most passive of measures, is what gets employees to show up for work.

- Motivation is the buzz employees feel about their work and a desire to excel in it rather than just turn up.

- Commitment is about feeling part of the wider company, in contrast to motivation, which works at an individual level.

- Advocacy covers advocacy for the company and its products/services.

- Engagement is a combination of all the preceding factors. An engaged worker is satisfied, motivated and committed, and is an advocate for the company and what it produces.

Hewitt Associates describe engagement as "the measure of an employee's emotional and intellectual commitment to their organization and its success" - in other words, a hearts and minds philosophy. Hewitt views engagement as an outcome of an employee's organisational experience. Engagement is characterised by behaviours that are grouped into three categories: say, stay and strive:

- Say - employees speak positively about the organisation.

- Stay - employees have an intense desire to be a member of the organisation despite other opportunities.

- Strive - employees spend time, effort and energy to contribute to business success.

The Corporate Leadership Council defines engagement as the extent to which employees commit to something or someone in their organisation - and how hard they try and how long they stay as a result of that commitment. Two types of commitment support effort:

- Rational commitment - the extent to which employees believe that managers, teams or the organisation is acting in their interest.

- Emotional commitment - the extent to which employees value, enjoy and believe in their jobs, managers, teams or the organisation.

This commitment has two outcomes:

- Discretionary effort - employees' willingness to go beyond the call of duty, such as helping others with heavy workloads, 
volunteering for additional duties, and looking for ways to perform their jobs more effectively.

- Intent to stay - employees' desire to stay with the organisation, based on whether they intend to look for a new job within a year, whether they frequently think of quitting, whether they are actively looking for a job or have begun to take tangible steps like making phone calls or sending out résumés.

\section{Measuring Employee Engagement}

Around 2002, the term "employee engagement" was used to describe a state of not only being satisfied with the job and workplace, but also giving one's best effort on a daily basis, and intending to stay (Branham 2006). Using this definition, consulting firms such as Gallup, Hewitt and others developed employee engagement surveys to help companies measure what percentage of their workforces was truly enthusiastic, dedicated and committed - in other words, engaged. Since 2006, hundreds of companies across a broad range of sectors have been switching from traditional employee satisfaction surveys to engagement surveys (Branham 2006). Branham (2006: 1) is convinced that employee engagement "is superior to employee satisfaction as a measure, because it sets a higher standard of what we want and expect from the workforce".

The Employee Engagement Report (2006), which covers research on 714 surveys across the three major geographic regions (North America, Europe, and Asia-Pacific) holds that there are two approaches to the issue of employee engagement:

- Programmatic - employee engagement is addressed through dedicated programmes or initiatives. Employee engagement surveys and special index scores focusing on the lowest performing survey items are used.

- Philosophical - employee engagement is an interesting management philosophy that is taken into consideration in human resource practices. The focus is on delivering results in specific business priorities for the year.

In general, companies with a dedicated employee engagement approach are more likely to use a tailored engagement survey to measure employees' level of engagement $(46 \%)$ than those who view engagement as an overall philosophy (10\%). However, a small percentage of the first group (8\%) say they do not measure engagement levels at all. Large organisations in the study (with over 10000 employees) are more likely to formally measure employee engagement than smaller organisations. Of the respondents of large companies, $81 \%$ said they used either a standard employee survey or a tailored employee engagement survey to evaluate levels of employee engagement, while $60 \%$ of the respondents of smaller companies used surveys for this purpose.

Arnott and Soobiah (2007b) found in their 2004 high-performance workforce study that high-performing organisations used methods and tools that were critical to successful transformation, for example employee engagement. The Employee Engagement Report (2006) found that respondents who measured engagement were more likely to report higher engagement levels. One-quarter said that their employees were, on average, "highly engaged", compared to only half that percentage of those who did not measure engagement. Similarly, $32 \%$ of respondents who did not measure engagement estimated their engagement levels as low; only $15 \%$ of those measuring did the same.

Thus, based on the above results, it can be assumed that where companies have hard data, they are more likely to see high engagement levels, and less likely to see low engagement levels. This also suggests that measuring employee engagement is of importance if companies seek to engage their employees or wish to improve current employee engagement.

\section{The Development of the Gallup Workplace Audit (GWA)}

During the mid-1980s, the Gallup Organisation decided to create a better feedback process for employers large and small: an opinion-based tool that would both release and direct the powers of feedback. The primary goal was to identify and measure the elements of worker engagement that were most powerfully linked to improved business outcomes - be they sales, growth, productivity, customer loyalty and so forth - and the generation of value. It began with conducting focus group interviews in var- 
ious companies across various industries. Each focus group included employees from each company's most productive departments. Over the last 25 years Gallup has been conducting thousands of such focus group interviews.

From the focus group interviews Gallup developed comprehensive surveys, including questions related to all aspects of employees' work experiences. These surveys were then administered to over a million employees (Buckingham and Coffman 1999). Initially five factors emerged:

1) Work environment/procedures. This factor addressed issues relating to the physical work environment, such as safety, cleanliness, pay, benefits and policies.

2) Immediate supervisor. This factor addressed issues relating to the behaviour of the employees' immediate supervisor, such as selection, recognition, development, trust, understanding and discipline.

3) Team/co-worker. This factor addressed issues relating to the employees' perceptions of team members, such as cooperation, shared goals, communication and trust.

4) Overall company/senior management. This factor addressed issues relating to company initiatives and leaders, such as the employees' faith in the company's mission and strategy, or in the competence of the leaders.

5) Individual commitment/service intention. This factor addressed issues relating to the employees' sense of commitment to the company and to its customers, such as the employees' pride in the company, likelihood to recommend the company to friends as a place to work, likelihood to stay with the company for their whole career, and desire to provide excellent service to customers.

Following this factor analysis, various regression analyses were performed on the data to identify some of the most powerful questions within the data set. The result was a 12-question survey in which employees are asked to rate their responses to each question on a Likert-type scale of one to five. These 12 questions are then subjected to a confirmatory factor analysis (see Buckingham and Coffman 1999). These questions can be pictured as a mountain climb from the moment an employee assumes a new role to the moment of full engagement in that role. The climb has four stages:
1) Base camp: "What do I get?" When employees start a new role, they want to know what is expected of them and what they will get from this role. This then leads to Camp 1.

2) Camp 1: "What do I give?" At this stage employees focus on their individual contributions and how other people perceive them (that is, whether others value their performance or not).

3) Camp 2: "Do I belong here?" At this stage of the climb employees want to know whether they fit here or not.

4) Camp 3: "How can we all grow?" This is the most advanced stage of the climb. Here employees want to make things better, to learn, to grow, to innovate.

In essence, Gallup has empirically determined employee engagement to be a significant predictor of desirable organisational outcomes (Luthans and Peterson 2002: 377), such as customer satisfaction, retention, productivity and profitability (see Buckingham and Coffman 1999).

The above discussion leads to the following hypothesis:

Work engagement, as measured by the GWA, can be defined as a four-dimension construct with acceptable levels of internal consistency for each of its sub-scales.

\section{METHOD}

\section{Research Design}

The study used a cross-sectional research design. Cross-sectional designs are appropriate where groups of subjects at various stages of development are studied simultaneously (Leedy and Ormrod 2013).

\section{Participants}

All employees (7500) of a South African petrochemical company were targeted. A total of 2 588 questionnaires were returned, with all found usable for data analysis. This represents a $34.50 \%$ response rate, given that there were 2588 potential respondents (see Table 1).

As for the demographic breakdown of the company, the questionnaire only made provision for the inclusion of information on the individual's job level, organisation and years in po- 
sition, and actual division, department and area. This breakdown is presented in Table 1.

Table 1: Characteristics of the participants

\begin{tabular}{llrr}
\hline Item & Category & $\begin{array}{c}\text { Frequ- } \\
\text { ency }\end{array}$ & $\begin{array}{c}\text { Percent- } \\
\text { age }\end{array}$ \\
\hline Job Level & Monthly salaried & & \\
& employee (MSP) & 1810 & 69.9 \\
& Salaried employee & 553 & 21.4 \\
& (SP) & & \\
& Team leader (area & 223 & 8.6 \\
& leader, group leader, & & \\
& section leader) & & \\
& Missing values & 2 & 0.1 \\
& Total & 588 & 100.0 \\
Years in & 6 months & 163 & 6.3 \\
Position & 6-12 months & 132 & 5.1 \\
& 1-2 years & 295 & 11.4 \\
& 2-5 years & 316 & 12.2 \\
& 5-10 years & 340 & 13.1 \\
& 10-20 years & 555 & 21.4 \\
& 20+ years & 785 & 30.3 \\
& Missing value & 2 & 0.1 \\
& Total & 2588 & 100 \\
\hline
\end{tabular}

\section{Procedure}

The assessment of levels of employee engagement is a biannual event in the company from which the sample was drawn. As such, this assessment is endorsed by the executive leadership, and has also been agreed to by key stakeholders such as organised labour. The process is overseen and managed by a shared services company. Employees are alerted to the biannual assessment by means of an e-mail and daily shop floor forums informing them that the questionnaire is to be distributed. An ethical procedure is followed by ensuring anonymity in their participation, as well as informed consent and the right to withdraw or not partake in the survey.

Employees who have internet and/or e-mail access (more than half the workforce) receive the questionnaire electronically and submit the data directly to a server of an external service provider. This further ensures that they cannot be identified, nor can responses be tampered with. The other employees receive printed questionnaires via the human resource unit, which receives the completed questionnaires in sealed envelopes. As names are not required, confidentiality is maintained. The paper questionnaires are delivered to an independent external research organisation that captures and verifies the data. The electronic and paper data are then collated into one data set that is analysed and reported on per division. The raw data are not returned to the client company. Changes in trends are however tracked by comparing the results of each survey with the results of previous surveys.

\section{Measuring Instrument}

For the purpose of this study, one survey form was used, namely the Gallup Workplace Audit that measures employee engagement. This instrument was developed from the 1950's through a series of management research with thousands of focus group interviews (Vale 2011). It consists of an overall organisational satisfaction item and 12 employee engagement items that measure the respondents' perceptions of their workplace. During the 1980s, the survey was reduced from 100-200 items to just thirteen statements, known as the GWA or Q12 (Vale 2011).

or Q12. T The responses to the 12 items are registered on a five-point scale varying from 1 (strongly disagree) to 5 (strongly agree). A metaanalysis of 4172 business units (Harter 1999) obtained a Cronbach's alpha of 0.91 . A study by Janse van Rensburg (2005) on the relationship between leadership styles and work-related attitudes reported a Cronbach's alpha of 0.90 (based on an aggregate data set with $\mathrm{N}=36$ ).

\section{Statistical Analysis}

All statistical analyses were performed with the 15.0.0 version of the SPSS software application. Descriptive statistics such as frequency counts were used to describe the sample.

Scale reliability was determined by means of a Cronbach's alpha coefficient. Sampling adequacy and sphericity were measured through the Kaiser-Meyer-Olkin Measure of Sampling Adequacy and Bartlett's Test of Sphericity respectively. The underlying structure of the questionnaire was determined by principal component analyses with varimax rotation.

\section{RESULTS}

According to Coetsee (2006), it is required to conduct the Kaiser-Meyer-Olkin (KMO) Measure of Sampling Adequacy (MSA) and the Bartlett's Test of Sphericity tests before factor anal- 
ysis can proceed. The results of the KMO for the WGA are reported in Table 2.

Table 2: KMO and Bartlett's test results

\begin{tabular}{lcc}
\hline $\begin{array}{l}\text { Kaiser-Meyer-Olkin Measure of } \\
\text { Sampling Adequacy }\end{array}$ & .956 \\
Bartlett's Test of & Approx. & \\
Sphericity & chi- & \\
& square & 25692.343 \\
& Df & 4278 \\
& Sig. & \\
& p-value & .000 \\
\hline
\end{tabular}

Hair et al. (1998) state that a result of 0.6 and higher is required for the MSA to be acceptable. From Table 2 it is clear that the data set complied with the requirements for sampling adequacy (0.956) and sphericity, and could thus be subjected to factor analysis.

Since the KMO and Bartlett's test indicated that the sample was adequate, the next step was to perform a factor analysis on the 12 items. First, a matrix of intercorrelations between the 12 items was set up. Secondly, a principal component analysis was conducted based on the matrix of intercorrelations. The results are displayed in Table 3.

Analysis of the eigenvalues (larger than 1) showed that only one factor could be extracted, which explained 54\% of the total variance. This result excluded the need for a second-order factor analysis (see Allyn and Yen 1979; Kaplan 1987; Kerlinger 1992; Schepers 1992; Gregory 1996; Hair et al. 1998; Kerlinger and Lee 2000).

Because previous studies (Langford 2009; Havenga et al. 2011) confirmed a four-factor so- lution for the GWA, and a one-factor solution did not make sense, it was decided to specify the four factors. A principal component analysis with a varimax rotation with Kaizer normalisation was used to analyse the factor structure of the GWA. The results are reported in Table 4.

Inspection of the rotated factor structure shows that, by using this method of analysis, the four factors extracted may be labelled as follows, based on the clustering of the items in each of the four factors. The first factor (labelled Clarity on required contribution) included the following items: I have the materials and equipment to do my work right (0.796); I know what is expected of me at work (0.772); I do know what this company wants to achieve (0.565); At work, I have the opportunity to do what I do best every day (0.447).

The second factor (labelled Opportunity to development) included the following items: Over the past six months I have made progress at work (0.837); I have opportunities to learn and grow at work (0.710); Someone at work encourages my development (0.556).

The third factor (labelled Personal recognition) included the following items: In the last seven days, I have received recognition or praise for doing good work (0.851); At work, my opinions seem to count (0.535); I know that there are people at work that care about me (0.5).

The fourth and last factor (labelled Quality of relationships) included the following items: I have really good friends at work (0.847) and I share a sense of commitment to the work I do with my colleagues $(0.638)$.

Table 3: Factor analysis: Total variance explained

\begin{tabular}{|c|c|c|c|c|c|c|c|c|c|}
\hline \multirow[t]{2}{*}{ Component } & \multicolumn{3}{|c|}{ Initial eigenvalues } & \multicolumn{3}{|c|}{$\begin{array}{c}\text { Extraction sums of squared } \\
\text { loadings }\end{array}$} & \multicolumn{3}{|c|}{$\begin{array}{l}\text { Rotation sums of } \\
\text { squared loadings }\end{array}$} \\
\hline & Total & $\begin{array}{l}\% \text { of } \\
\text { variance }\end{array}$ & Cumulative & Total & $\begin{array}{l}\% \text { of } \\
\text { variance }\end{array}$ & $\begin{array}{c}\text { Cumulative } \\
\%\end{array}$ & Total & $\begin{array}{l}\% \text { of } \\
\text { variance }\end{array}$ & $\begin{array}{c}\text { Cumulative } \\
\%\end{array}$ \\
\hline 1 & 6.528 & 54.399 & 54.399 & 6.528 & 54.399 & 54.399 & 2.305 & 19.211 & 19.211 \\
\hline 2 & .844 & 7.035 & 61.433 & .844 & 7.035 & 61.433 & 2.287 & 19.056 & 38.267 \\
\hline 3 & .651 & 5.423 & 66.857 & .651 & 5.423 & 66.857 & 2.047 & 17.054 & 55.321 \\
\hline 4 & .632 & 5.267 & 72.124 & .632 & 5.267 & 72.124 & 2.016 & 16.803 & 72.124 \\
\hline 5 & .557 & 4.644 & 76.768 & & & & & & \\
\hline 6 & .495 & 4.127 & 80.895 & & & & & & \\
\hline 7 & .455 & 3.791 & 84.686 & & & & & & \\
\hline 8 & .428 & 3.568 & 88.254 & & & & & & \\
\hline 9 & .397 & 3.311 & 91.565 & & & & & & \\
\hline 10 & .368 & 3.064 & 94.629 & & & & & & \\
\hline 11 & .325 & 2.710 & 97.339 & & & & & & \\
\hline 12 & .319 & 2.661 & 100.000 & & & & & & \\
\hline
\end{tabular}

Extraction method: Principal component analysis 
was used. Exploratory factor analysis resulted in a one-factor model of work engagement and showed acceptable internal consistency.

A review of the literature shows that the construct itself has a variety of definitions, models and measurement approaches. Engagement is the extent to which employees commit " rationally or emotionally " to something or someone in the organisation, how hard they work as a result of this commitment, and how long they intend to stay with the organisation (Verwey 2007). There is however general agreement that employee engagement is a significant variable in understanding individual satisfaction and organisational performance dimensions (Pfeffer 1998).

This research was conducted in one organisation in South Africa. This was a significant advantage, since variances due to differences in organisational culture, leadership style and other factors that may impact on employee engagement were eliminated. Furthermore, as the survey was completed by all respondents over a period of two weeks, variances due to intraorganisational factors were minimal. The sample size of more than 2588 respondents also means that issues of sampling adequacy were not a problem.

The data were first subjected to an item analysis to establish scale and item reliability. In keeping with the results of similar studies, it was found that none of the items needed to be eliminated from the scale, and that the scale itself had a very high reliability (Cronbach's alpha of 0.923). These results would seem to suggest that although the scale itself is highly reliable since it confirms previous studies (Harter 1999; Janse van Rensburg 2005; Vale 2011), the construct validity might be questionable.

Next, a factor analysis was performed to determine whether indeed the items reflected the GWA four-factor model. The analysis showed that the questionnaire was based on one factor only. Because one factor didn't make sense for the GWA, it was decided to force the extraction of four factors. This resulted in a factor structure that was very different from the four factors measured by the GWA. The four factors identified in this study were clarity on required contribution, opportunity to development, personal recognition and quality of relationships.

\section{CONCLUSION}

The GWA proved to be a valid and reliable measuring instrument of employee engagement. This confirms that an international survey can be utilised effectively in the South African context.

\section{RECOMMENDATIONS}

This study was the first of such scope in South Africa. It has therefore created a significant point of departure for similar research in this country. The fact that the results did not simply confirm the construct validity of the GWA approach to the definition and measurement of employee engagement makes for interesting and potentially valuable further research opportunities. From a practitioner perspective, it also implies that any approach to employee engagement requires significantly more thought to ensure that the definition and measurement of such engagement are applicable to the organisation and context in question.

For organisations wishing to measure employee engagement, the practical implications of the results are that, firstly, they need to be clear on their own understanding of the construct, and, secondly, they have to make sure that they identify through a rigorous process their own key drivers of employee engagement. The assumption that employee engagement is a generic construct with the same meaning across organisations and national cultures may not be true. The measurement of engagement with an international instrument may not yield the correct interpretation of engagement in South Africa. Organisations should rather consider finding means to measure key drivers of engagement applicable to their industry and their work context.

Given the comments on the limitations and practical implications of this study, additional research should be conducted to compare different measurement approaches to employee engagement, as well as to establish the degree to which employee engagement is influenced by organisational practices and national culture. Such research should answer the questions:

- Is employee engagement an organisationspecific construct?

- Is employee engagement also a function of national culture? 
Since only one GWA factor was identified in this sample of one organisation, the following are recommended:

- The reliability and validity of the GWA should be tested in various organisations per industry so as to determine whether the construct of engagement is similar across industries or relevant in certain industries only.

- A quantitative study should be conducted to compile an engagement survey more relevant to the South African context.

\section{LIMITATIONS}

Although this study was robust from the perspective of sample size and statistical analysis, it may indeed have been useful to use other engagement surveys and include more than one organisation so as to verify construct validity. Organizations from other industries should also be tested and the degree to which employee engagement is influenced by organizational practices and organizational culture should be considered. This would have assisted in determining whether the lack of construct validity was specific to the Gallup instrument or whether it was related more to other influences, such as organisational or national culture.

\section{REFERENCES}

Allyn MJ, Yen WM 1979. Introduction to Measurement Theory. Montery, CA: Brooks and Cole.

Arnott J, Soobiah S 2007a. High performing businesses: In search of a performance anatomy. Management Today, June, 23(5): 47-51.

Arnott J, Soobiah S 2007b. High performing companies: Changing ahead of the curve. Management Today, 23(6): 13-17.

Bhatnagar J 2007. Predictors of organisational commitment in India: Strategic HR roles, organisational learning capability and psychological empowerment. International Journal of Human Resource Management, 18(10): 1782-1807.

Blanchard K 2007. Is your organisation high performing? Management Today, 23(6): 10-12.

Branham FL 2006. E-Letter, 8: 1-3.

Buckingham M, Coffman C 1999. First, Break All the Rules: What the World's Greatest Managers do Differently. New York, NY: Simon and Schuster.

Burke RJ, Cooper CL 2004. Leading in Turbulent Times. Oxford: Blackwell.

Burke RJ, Cooper CL 2005. Reinventing Human Resource Management: Challenges and New Directions. London: Routledge.

Burkea RJ, Ngbe E 2006. The changing nature of work and organizations: Implications for human re- source management. Human Resource Management Review. 16(2): 86-94.

Coetsee JHC 2006. Barriers-to-change in a Governmental Service Delivery Type Organisation. Ph D Thesis, Unpublished. University of Johannesburg (RAU), Johannesburg.

Conradie D 2005. Happy Employees - Lead to Happy Bottom Line. HR Future, p. 37.

Cooper CL, Burke RJ 2002. The New World of Work. London: Routledge.

Cortina JM 1993. What is coefficient alpha? An examination of the theory and applications. Journal of Applied Psychology, 78(1): 98-104.

Cropanzano R, Mitchell MS 2005. Social exchange theory: An interdisciplinary review. Journal of Management, 31: 874-900.

De Beer G 2007. People issues - top the strategic agenda. Management Today, 23(7): 40-44.

Demerouti E, Cropanzano R 2010. From thought to action: Employee work engagement and job performance. Arnold B Baker, Michael P Leiter (Eds): Work Engagement: A Handbook of Essential Theory and Research, New York: Psychology Press. 147-163.

Employee Engagement Report 2006. Skillman NJ: Blessingwhite.

Gregory R 1996. Psychological Testing. History, Principles, and Applications $2^{\text {nd }}$ Edition. Boston: Allyn and Bacon.

Hair JF, Anderson RE, Tatham RL, Black WC 1998. Multivariate Data Analysis. $5^{\text {th }}$ Edition. Upper Saddle River, NJ: Prentice-Hall International.

Harter JK 1999. The meta-analysis. In: M Buckingham, C Coffman (Eds.): First, Break All the Rules: What the World's Greatest Managers do Differently. New York: Simon and Schuster.

Havenga W, Wait K, Stanz K. 2011 Evaluating the difference in employee engagement before and after business and cultural transformation interventions. African Journal of Business Management, 5: 22.

Janse van Rensburg N 2005. Leadership Styles and Work-Related Attitudes in Subordinates. Ph D Thesis, Unpublished. University of Johannesburg (RAU), Johannesburg.

Joo BK, Mclean GN 2006. Best employer studies: A conceptual model from a literature review and a case study. Human Resource Development Review, 5(2): 228-257.

Kahn WA 1990. Psychological conditions of personal engagement and disengagement at work. Academy of Management Journal, 33: 692-724.

Kaplan RM 1987. Basic Statistics for Behavioural Sciences. Boston: Allyn and Bacon.

Kerlinger FN 1992. Foundations of Behavioural Research. $3^{\text {rd }}$ Edition. Harcourt Brace College.

Kerlinger FN, Lee HB 2000. Foundations of Behavioural Research. $4^{\text {th }}$ Edition. New York: Harcourt College.

Koyuncu M, Burke RJ, Fiksenbaum L 2006. Work engagement among women managers and professionals in a Turkish bank: Potential antecedents and consequences. Equal Opportunities International, 25(4): 299-310.

Langford PH 2009. Measuring organisational climate and employee engagement: Evidence for a $7 \mathrm{Ps}$ 
model of work practices and outcomes. Australian Journal of Psychology, 61(4): 185-198.

Lawler EE 2003. Treat People Right. San Francisco, California: Jossey-Bass.

Leedy P, Ormrod J 2013. Practical Research: Planning and Design. New York: Pearson.

Luthans F, Peterson SJ 2002. Employee engagement and manager self-efficacy. Implications for managerial effectiveness and development. Emerald Group Publishing, 21(5): 376-387.

Maslach C, Schaufeli W, Leiter MP 2001. Job burnout. Annual Review of Psychology, 52: 397-422.

Mollen A, Wilson H 2010. Engagement, telepresence and interactivity in online consumer experience: Reconciling scholastic and managerial perspectives. Journal of Business Research, 63(9): 919-925.

Müller R, Turner R 2010. Leadership competency profiles of successful project managers. International Journal of Project Management, 28(5): 437-448.

Nel C 2008. New economy leadership: Now for something different. Management Today, Yearbook 2008, 23(10): 12-15

Parker A 2008. World-class organisations: Only a developed country phenomenon? Management Today, Yearbook 2008, 23(10): 16-18.

Pfeffer J 1998. The Human Equation: Building Profits by Putting People First. Boston, MA: Harvard Business School.

Richman A 2006. Everyone wants an engaged workforce. How can you create it? Workspan, 49: 36-39.

Robinson D, Perryman S, Hayday S 2004. The Drivers of Employee Engagement. Brighton: Institute for Employment Studies.
Rothbard NP 2001. Enriching or depleting? The dynamics of engagement in work and family roles. Administrative Science Quarterly, 46: 655-684.

Saks AM 2006. Antecedents and consequences of employee engagement. Emerald Group Publishing, 27(7): 600-619.

Schepers JM 1992. Toetskonstruksie: Teorie en Praktyk. Johannesburg: RAU.

Shaughnessy JJ, Zechmeister EB 1997. Research Methods in Psychology. $4^{\text {th }}$ Edition. New York: McGraw-Hill.

Shuck B 2011. Integrative literature review: Four emerging perspectives of employee engagement: An integrative literature review. Human Resource Development Review, 10 (3): 304-328.

Tasker J 2004. Engagement Equals Productivity. Personnel Today, 5 October, 8-9.

Truss C, Shantz A, Soane E, Alfes K, Delbridge R 2013. Employee engagement, organisational performance and individual well-being: Exploring the evidence, developing the theory. The International Journal of Human Resource Management, 24(14): 2657-2669.

Vale F 2011. A Measurement of Employee Engagement Using the Gallup Q12 Workplace Audit. Honours Dissertation, Unpublished. National college of Ireland.

Verwey A 2007. Employee Engagement. Unpublished.

Wollard KK 2011. Quiet desperation another perspective on employee engagement. Advances in Developing Human Resources, 13(4): 526-537. 